\title{
Una etnohistoria poco étnica Nociones de lo autóctono en una comunidad campesina peruana*
}

\author{
Frank Salomon
}

$\mathrm{L}$ OS AÑOS noventa, época en la cual el significado transcultural de la "historicidad" llegó a ser tema candente dentro de la teoría antropológica, alteraron algunos fundamentos de la vocación etnohistórica. ¿Cuánta variación cultural existe entre los diversos conceptos del tiempo y del cambio? ¿Hasta qué punto aquellas diferencias gobiernan la actuación histórica de los pueblos? Al contemplar tales preguntas, el debate teórico dentro de la etnohistoria viró de la posición de crítica metodológica a la de liderazgo heurístico dondequiera que se pretendía investigar las historias de los "otros". Aunque Oceanía fue la zona que llevó la voz cantante durante el famoso debate entre Sahlins y Obeyesekere, los estudiosos andinos y amazónicos aportaron contribuciones no menos creativas (Abercrombie, 1998; Urton, 1990; Carneiro y Viveiros, 1985; Basso, 1985).

Algunos esfuerzos para reconceptualizar la etnohisto-

FRANK SALOMON: Universidad de Wisconsin, Madison. Traducción de кimbra smith, Universidad de Chicago.

\footnotetext{
* El autor agradece cordialmente a la Junta Comunal de la comunidad campesina San Andrés de Tupicocha por haberle facilitado el acceso a su archivo en 1995, 1997 y 2000. Se aprecia especialmente la colaboración de León Modesto Rojas Alberco. Este ensayo se basa en investigaciones realizadas con el apoyo de la National Science Foundation y la Wenner-Gren Foundation, y con un subsidio adicional de la facultad de posgrado de la Universidad de Wisconsin-Madison. Se le agradece a Mercedes Niño-Murcia su valiosa ayuda en la redacción del ensayo y su colaboración con la traducción.
}

ria (Krech, 1991) coincidieron con los festejos y debates en torno al quincentenario colombino de 1992. Otros se relacionaron con el anhelo de parte de los líderes indígenas para definir alternativas de oposición más compatibles que el decaído paradigma clasista con el sentido de "ser un pueblo" según criterios culturales. Los países andinos (Albó, 1999), entre otros, presenciaron una resurgente preocupación con las identidades indígenas, las cuales con creciente regularidad fueron descritas como identidades "étnicas". Esta coincidencia favoreció una tendencia a confundir la etnohistoria con el estudio histórico de las identidades étnicas. Sobre todo en los textos de difusión, la reivindicación de las "raíces" culturales se elevó a una narrativa-maestra que gobernaba la exégesis periodística de las conciencias históricas populares. Esta tendencia, seguramente relacionada también con el universalmente sonado multiculturalismo norteamericano, sigue dominando mucha literatura sobre los movimientos neoindigenistas en Ecuador, Bolivia y la Amazonia.

Dentro de aquel panorama, Perú presenta una excepción. Los especialistas peruanistas (Poole, 1997; De la Cadena, 2000) se han mostrado incisivos al demostrar cómo el paradigma "étnico" muchas veces se construyó con base en las taxonomías raciales anteriores con ligeras modificaciones terminológicas, en vez de construirse sobre un diálogo etnográfico intensivo y renovador. El presente ensayo enfatiza los procesos no "étnicos" que generan la identidad en el Perú. Demuestra cómo una pequeña 
región genera una "etnohistoria" strictu sensu (o sea, un conocimiento de la historia desarrollado internamente) que cuestiona las ideas tradicionales sobre la etnicidad del pueblo andino, y también, cuestiona las ideas históricas tradicionales acerca de la importancia decisiva del "encuentro" colonial inicial. (Nótese que el motivo del "primer encuentro" predominó en el debate teórico a partir de Islands of History por Marshall Sahlins, publicado en 1985.)

Teóricamente, los estados latinoamericanos poscoloniales confirieron en todos sus pueblos una condición de ciudadanía que implicaba la libertad y presuponía el respeto social. En la práctica, para los peruanos rurales que viven bajo la sombra de estigmas raciales y/o lingüísticos, estos atributos tienen que conquistarse nuevamente a cada paso. En la provincia de Huarochirí (departamento de Lima), como suele ser el caso en toda la sierra andina, los campesinos encuentran problemática la retórica de la "etnicidad", porque conlleva un legado de discursos indigenistas pronunciados desde arriba hacia abajo. Muy lejos de connotar un pluralismo sano, como sí se hace en el discurso académico internacional, el término "indígeconnotaciones raciales inaceptables (Abercrombie, 1991: 96-100; De la Cadena, 2000).

Durante mucho tiempo, los antropólogos han evitado pronunciarse claramente sobre este problema. Los etnógrafos clásicos de la región —el grupo de Matos Mar en la década de 1950 (p.e., Matos, 1953, 1958; Guillén, 1953)— utilizaban la palabra "indígena” como jerga profesional para describir a los pobladores, como si con aquella palabra se describiera un hecho natural. Sin embargo, no sugirieron que la palabra indicaba un elemento de autodefinición. De hecho, las etnografías del Perú central (Adams, 1959; Castro Pozo, 1946; Escobar, 1973; Long y Roberts, 1978; Smith, 1989; Tschopik, 1947) dan la impresión de que los campesinos de la sierra central se autoconceptualizan hasta hoy como peruanos genéricamente rurales, no adscritos a ninguna categoría étnica. Según contextos y períodos, más bien prefieren identidades regionalistas ("huarochiranos", etcétera), de clase ("campesinos") o a veces de "mestizos" en el sentido de "gente sin raza definida". Tal vez este distanciamiento intencionado de la visión del Perú como un país compuesto de "gru-

pos étnicos" o "razas" es en sí la razón por la cual existen pocas etnografías del centro de Perú, y por qué las que existen acostumbran enfocarse en la organización económica más que en problemas específicamente culturales.

La indefinición sobre las identidades rurales, rasgo que una vez parecía un defecto en la metodología etnográfica, ahora parece aconsejable de acuerdo con el aforismo "Es mejor callar sobre lo inefable". ${ }^{1}$ A pesar de varios avances en la interpretación de la usanza popular de términos como mestizo (Barragán, 1992; De la Cadena, 1996: 115), la etnografía aún carece de un lenguaje adecuado para describir las ideas populares, intracomunitarias y regionales sobre "quiénes somos" los peruanos rurales. Las múltiples formulaciones categóricas de "diferencias" que los huarochiranos utilizan al tratar con forasteros o con ciudadanos urbanos (por ejemplo, en frases que describen ideas de clase social, de raza "mestiza", de regionalismo o terruño, de idiosincrasia rural, o con el lenguaje de "costumbres" o "folclor") obviamente obedecen a determinados contextos y dependen de sus instrumentalidades. ${ }^{2}$ El concepto de una "etnicidad situacional" se puede aplicar con brío, pero no ayuda mucho a definir las "identidades" en el sentido normal de la palabra. Es decir, no define categorías de ego colectivo que impliquen una fuerte solidaridad o premisas sobre la reciprocidad moral. Si estos términos autodescriptivos (situacionales y parciales, por supuesto) no bastan para caracterizar "quiénes somos", mucho menos se justificaría importar categorías étnicas adscriptivas ya rechazadas por la mayoría de los serranos que tampoco llevan a la claridad analítica.

Lo que sí deseo en este artículo es evocar etnográficamente las nociones -implícitas pero a la vez profundamente experimentadas - del ser colectivo que los comunitarios emplean entre ellos. Este trabajo requiere que la etnografía deje de presuponer la existencia

\footnotetext{
1 "Whereof one cannot speak, be silent", dicho atribuido al filósofo Ludwig Wittgenstein.

${ }^{2}$ Por ejemplo, la mayoría de los hogares Huarochirí son "semi-proletarios" (Janvry, 1981: 84) e informalmente comerciales tanto como campesinos; situacionalmente "andinos" tanto como "mestizos"; urbanos tanto como rurales; nacionalistas tanto como provinciales; y consumidores de los medios televisivos mundiales tanto como participantes en el folclor.
} 


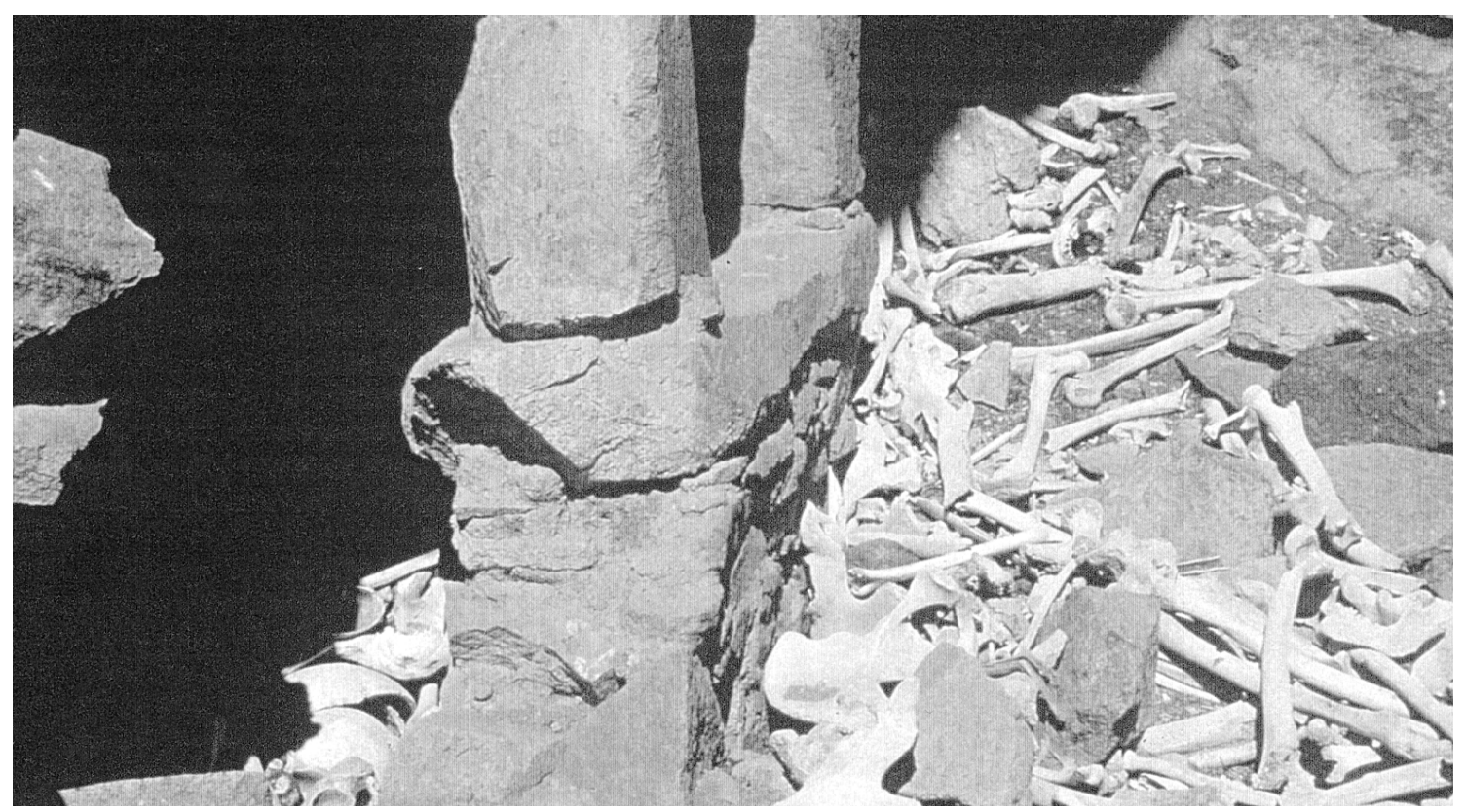

FIGURA 1: Restos de los "gentiles", región de Huarochí; foto: Frank Salomon

continuada y subyacente de la dicotomía colonial básica entre nativos y no nativos. Al contrario, debemos seguir a los comuneros, haciendo lo que ellos hacen: encajar el problema de la "autenticidad" por vía de cuestionamiento general, y no contentarnos con la simple trasvaloración de la dicotomía que se esconde tras el vocablo "indígena".

En el Perú rural, en contraste con los hechos recientes en Bolivia y Ecuador, la conquista de la dignidad social implica lo que De la Cadena (2000: 6-7 y passim) ha llamado la "desindianización" del concepto de lo autóctono. Para los peruanos que se quedan en el campo, inscritos en comunidades campesinas jurídicamente establecidas, el quehacer de desasociar la identidad local o comunal del estigma indígena implica problemas de orden conceptual. Sucede así porque, legalmente, la legitimidad de las comunidades campesinas se basa en dos atributos que el "indigenismo oficial" del "oncenio" o dictadura del presidente Augusto Leguía (1919-1930) ahistóricamente definió como la esencia gemela de la terratenencia "tradicional": la posesión inmemorial, y la propiedad colectiva de tierras. En las Solicitudes de Reconocimiento, la posesión inmemorial normalmente se comprueba demostrando la continuidad por herencia desde lo que el estado colonial llamaba "indios tributarios". La propiedad colectiva usualmente se comprueba aduciendo el ayllu (grupo corporativo basado en la descendencia, también llamado parcialidad) u otra formación andina como control institucional sobre el uso de la tierra. El ayllu es un mecanismo organizador de una antigüedad al menos incaica. Un derecho cívico altamente valorado en la modernidad —el título de comunero- se retiene únicamente con la retención adicional de índices de la misma condición colonial que el proyecto moderno pretende superar. Por esta razón, los documentos en los cuales las colectividades campesinas se proclaman como comunas, a veces contienen revisionismos audaces en cuanto al significado de la condición colonial. Para los años 1920, Glave (1991: 248-262) ha detallado la autohistoriografía asombrosamente heterodoxa voceada en un pueblo cerca del Cuzco.

El presente trabajo se enfoca en un pueblo que pertenece a una región mucho menos "nativa" o "indígena" según los criterios populares. Propone que Huarochirí ha construido su identidad justamente haciendo frente a 
la contradicción que se acaba de esbozar. El pueblo en cuestión es Tupicocha, comunidad campesina reconocida que controla tierras desde aproximadamente 2500 hasta 4800 metros sobre el nivel del mar, en el escarpado flanco oeste de los Andes, el cual dista un día de viaje desde Lima, y se ubica cerca de la cabecera del río Lurín. De los 1543 habitantes del pueblo (según el censo de 1993; INEI, 1994: 200), quizás la mitad vive exclusivamente en el núcleo de la comunidad, ubicado en un camino secundario difícil a unos $3321 \mathrm{~m}$ de altura (Stiglich, 1992: 1084). Dentro de esta mitad, la mayoría, pero no todos, pertenecen a los 143 hogares registrados hacia 1997 como comuneros. Los demás o tienen doble domicilio, en Tupicocha y en Lima, o viven permanentemente en Lima, o viven en los caseríos "anexos" esparcidos por las alturas. También hay quienes se llaman "independientes", es decir, agricultores que no se inscriben en la comunidad. A pesar de su ubicación a poca distancia de la capital, y a pesar de su economía en buena parte "semiproletaria" (Weismantel, 1988), en 2001 Tupicocha todavía carece de luz eléctrica, de agua potable, y de infraestructuras indus- plejo de acueductos, acequias, terrazas y pastizales amurallados, cuya construcción se remonta a la antigüedad prehispánica y se refuerza en cada ciclo anual bajo la administración de la comunidad. Para sincronizar las interminables labores infraestructurales, la comunidad se moviliza en la forma de diez ayllus o parcialidades, que son continuaciones lineales de los ayllus de Checa descritos en el Manuscrito de Huarochirí de 1608 (?) (Taylor, 1987; Salomon y Urioste, 1991; y otras ediciones; Astete, 1997; Martínez 1996; Rostworowski, 1978; Salomon, 1997).

En muchos otros aspectos, como por ejemplo, el sentimiento profundo hacia los cerros y lagos deificados y la intrínseca ritualidad de los ayllus, la cultura huarochirana parece intensamente "andina", excepto por la cuestión del idioma, puesto que los huarochiranos únicamente hablan español. La mayoría de ellos viaja con frecuencia a Lima, donde laboran como vendedores, estudiantes o trabajadores. En la capital se les adscribe la identidad de "serranos" o "provincianos" (y hasta términos más peyorativos a sus espaldas, entre ellos el odioso "indio"). La alternación de contextos pone el dedo en la llaga en cuanto a la dignidad del campesino, produciendo una cierta inconsistencia ideológica. ¿Qué suerte de identidad crece en torno a esta alternación rápida entre dos contextos, uno donde la subsistencia depende de herencias complejamente andinas, y otro donde la dignidad se compra al precio de una disociación aparente del primero?

\section{UNA DISCONTINUIDAD NECESARIA: EL PROBLEMA DE LOS MUERTOS PRECOLOMBINOS}

Los muertos precolombinos son designados como "gentiles", y son conocidos también como "tapados", "los hermosos abuelos”, etcétera (Allen, 1982; Fuenzalida, 1979; Gose, 1994: 129-130; Harris, 1982; Paerregard, 1987; Valderrama, 1980). Sus restos se encuentran fácilmente en las cuevas y tumbas saqueadas, situadas en las afueras de cada asentamiento huarochirano (Bueno, 1992). De vez en cuando se descubren momias intactas, pero la gran mayoría de las cuevas y casas funerarias han sido destruidas, ya sea por los "extirpadores de idolatrías", que asolaron la región de Huarochirí durante el siglo XVII, o por los saqueadores de tiempos más recientes. Los "gentiles" se han convertido en un enfoque simbólico donde se condensan las preocupaciones sobre autoctonía e identidad.

Para los forasteros y los comuneros, los gentiles figuran entre las realidades locales más simbólicas y peligrosas. Los etnógrafos anteriormente citados enfatizan que los gentiles controlan celosamente a los vivos mediante su influjo en la agricultura y la salud. La preocupación de los vivos se expresa en ciertos gestos deferenciales que los comuneros realizan al pasar cerca de una tumba prehispánica: un saludo murmurado, un regalito de coca o tabaco, y esta ritualidad tiene aspecto político-legal.

Como sucede en la mayoría de los pueblos andinos, algunos restos precolombinos del pueblo circunvecino de San Damián han caído en manos del personal estatal (Isbell, 1997: 150). La presencia de las reliquias humanas causa malestar entre la policía nacional y los soldados acuartelados contra la guerrilla, así como entre los maestros locales y el personal que atiende los puestos de salud, ya que son percibidas como emisoras de una fuerza 
ligeramente maligna que no puede ser combatida por la ideología que acompaña al personal estatal.

Los policías que me mostraron dos cráneos en cofres modernos lo hicieron porque algunos sufrían de insomnios, atribuidos a la maligna influencia psíquica de los gentiles. Esperaban que yo, como presunto experto en restos óseos (antropólogo), identificara los cráneos como evidencias de homicidios, y por lo tanto, como evidencia forense que debería despacharse a otras oficinas de su propia institución, donde la ciencia seguramente las domesticaría. Los maestros de la escuela fiscal también me mostraron momias saqueadas que retenían con descuido en un almacén de la escuela primaria. La presencia de momias saqueadas en escuelas se debe a una práctica pedagógica ilegal pero casi universalmente difundida: los profesores exigen a sus alumnos la búsqueda de "tapados" para supuesta docencia de prehistoria, pero en realidad con una mezcla de finalidades contrabandistas y supersticiosas quizás no sin matiz racista. Sólo después de unos tragos y con cierto nerviosismo me los mostraron sin que yo lo pidiera. Esperaban que el antropólogo, en capacidad de científico, desacralizara los objetos nombrándolos como restos arqueológicos. Una vez oficialmente reducidos a patrimonio científico (categoría establecida por ley) cabrían sin ambigüedades dentro del currículum que ellos habían venido a enseñar.

Los comuneros también sienten malestar a causa de los gentiles, pero por motivos algo distintos. Juzgan peligroso y malo el sacar los huesos o las momias enteras de sus lugares de reposo. Consideran a los difuntos antiguos en chaucallas o estructuras funerarias (también llamadas chullpas, ${ }^{3}$ término generalizado en Perú), o en las cuevas, como vínculos con la tierra y con los cerros y lagos deificados. Los antiguos, hijos de las divinidades, son los "primeros y originales dueños", como los denomina un comunero. Mientras sus restos físicos existan, aun destrozados, ellos subsisten como personajes, ya que los seres humanos modernos utilizamos la tierra únicamente por su permiso. Si los gentiles se ofenden (por ejemplo, cuando sus tumbas son saqueadas o cuando los paseantes

${ }^{3}$ El término regional kullpi, común al norte del río Rímac, no se escucha con frecuencia en Huarochirí central. no dejan ofrendas ni saludos) pueden enviar una enfermedad característica. Se dice que Julio C. Tello —el arqueólogo pionero e hijo de Huarochirí que hizo las momias peruanas famosas en círculos científicos a principios del siglo XX- murió de dicha enfermedad. Los huaqueros (saqueadores) locales existen, pero son criticados por su "falta de respeto".

Sin embargo, al aceptar la identidad de "peruanos", al hacerse conocer entre la comunidad política más amplia como campesinado progresista, los huarochiranos se distancian de sus antiguos muertos: su propio linaje no les parece haber descendido de ninguna manera de los gentiles. A pesar del gran interés en la genealogía demostrado por los campesinos, los tapados en sus tumbas carecen de nombres individuales, con una excepción importante: los "dueños" deificados del agua, la pareja Pencollo y Mama Catiana, cuya presencia física se reconoce rindiendo culto anual a sus cráneos. Los ayllus supuestamente tienen ancestros fundadores, pero éstos no son identificados con los muertos prehispánicos. Los comuneros tampoco comentan sobre el origen de muchos apellidos comunes (Llacsañaupa, Vilcayauri, Cajahuaringa, etcétera) cuya etimología evidentemente no es europea. Si se les pregunta qué tipo de apellidos son éstos, contestan que son "peruanos", o que son típicos de la provincia de Huarochirí, pero jamás los asocian con ninguna "raza" ni con algún grupo étnico.

Por lo tanto, los comuneros encaran la tarea de definirse simultáneamente como herederos de los muertos antiguos, mas no como la continuación genealógica de su estirpe. Una frase respetuosa para referirse a las momias y restos óseos prehispánicos es "los hermosos abuelos", pero nadie los reclama como ancestros personales. Nunca escuché a nadie referirse a ellos como a "nuestros abuelos".

¿Cómo es posible que los gentiles sean los abuelos de la comunidad, sin que sean los abuelos de ningún comunero? En ciertas regiones andinas el observador de semejante anomalía avalaría la conocida mitología andina del pachakuti: el cataclísmico "torno o retorno del tiempo y espacio" que deja los mundos anteriores sumergidos bajo la superficie del mundo actual. Sin embargo, la noción de pachakuti figura con muy poca 


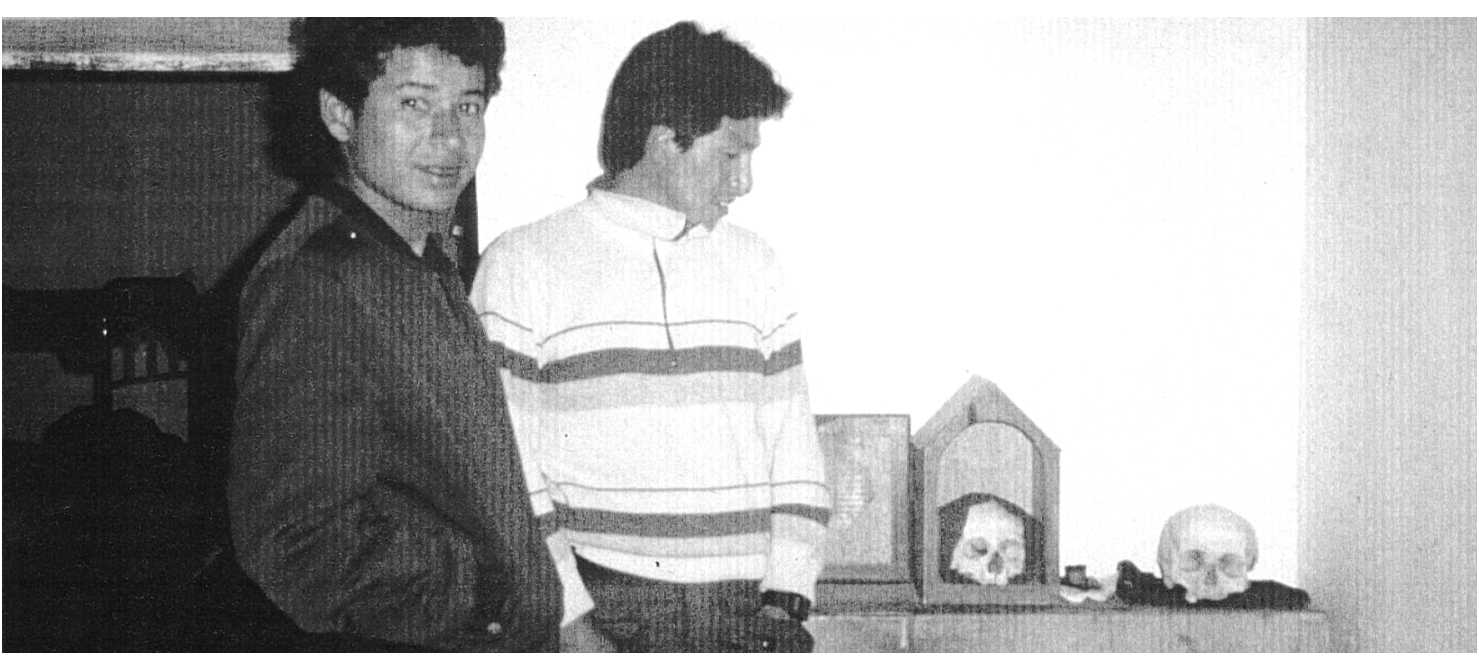

FIGURA 2: Cráneos mostrados al "científico"; foto: Frank Salomon

frecuencia en el discurso huarochirano; si existe la palabra pachakuti, ésta se conoce sólo a través de los textos escolares que hablan de los incas.

Más bien, los huarochiranos narran una historia fol-
Para los tupicochanos, el momento decisivo que separa a los gentiles de la gente moderna no corresponde a ninguno de los eventos que las ideologías rurales conocidas tratan como momentos claves, como la matanza judicial de Inkarrí ${ }^{4}$ o la Guerra del Pacífico entre 1879 y 1883, o reside en los eventos que la historiografía nacional trata como momentos decisivos, tales como la invasión española de 1532, las campañas de extirpación de idolatrías entre 1609 y 1670 , las sublevaciones del siglo XVIII, o la época bolivariana. Al estudiar su propio legado documental, los comuneros conceden importancia superior a una época generalmente considerada como oscura y sin carisma: la segunda mitad del siglo XVII. Esto es, el período del "colonialismo maduro", presentado por los historiadores de textos escolares como era de estabilidad,

\footnotetext{
${ }^{4}$ Inkarrí es nombre quechua del "Inka Rey" imaginado como figura mesiánica. La imaginada vuelta del Inka martirizado a América traería un milenio en el cual las relaciones blanco-indígenas serían invertidas. Inkarrí fusiona aspectos de Atahuallpa Inca, Túpac Amaru del régimen inca rebelde en Villcabamba, y Túpac Amaru II, el gran rebelde del siglo XVIII (Burga, 1988).
}

si no de estancamiento, representa para los tupicochanos una ruptura entre la prehistoria y la historia más decisiva aun que la invasión española.

\section{UNA CONTINUIDAD NECESARIA: EL ARGUMENTO DE LA HERENCIA MITO- HISTÓRICAY EL AUTO DE LOS MUERTOS}

$\mathrm{Al}$ igual que innumerables comunidades latinoamericanas, Tupicocha fundamenta sus reclamos territoriales en una colección de documentos coloniales y en largos litigios republicanos basados en ellos. Estos documentos se conservan en el Local Comunal, ${ }^{5}$ y uno de los expedientes más importantes es el Auto de los muertos (el título usado en los inventarios anuales). En términos académicos, este auto es una Provisión Real original de 1670 que aparentemente refleja las consecuencias rurales de la política real que intentaba exprimir adicionales ingresos tributarios para aliviar la crisis financiera que España vivía, cada vez más aguda, a lo largo del siglo XVII (Te Paske y Kline, 1982, v. I). En este documento, el virrey Conde de Lemus responde a ciertos tributarios, quienes se

\footnotetext{
${ }^{5}$ Un salón comunitario donde los socios de la comunidad llevan a cabo reuniones y otras actividades públicas y semipúblicas.
} 
quejan de hallarse obligados a pagar tributos por personas muertas. A manera de respuesta, la provisión dispone que los tributarios deben cubrir la retasa vigente en la máxima medida posible utilizando productos de las chacras (campos de producción agrícola) comunitarias, justificando cualquier déficit atribuible a fallecimientos o ausencias sólo después de dar cuenta del pago correspondiente.

Este documento no reconoce ninguna crisis especial en Huarochirí, ni tampoco responde a un problema fundamental: a saber, el encargar a los señores locales la cobranza del tributo sin concederles autoridad para actualizar las listas de tributarios. Aunque puede haber aliviado el problema en cierta manera superficial, el Auto no fue en su momento más que una instancia rutinaria de la defectuosa articulación entre imperio y pueblo tributario. No obstante, para los tupicochanos, el Auto de los muertos significa mucho más. Según ellos, es el fundamento de su tenencia legítima de las tierras comunitarias. Aún más: desde su perspectiva, sus libertades cívicas se arraigan en él.

Sorprendido al darme cuenta de la diferencia entre mi modo de comprender aquel documento y el de la junta directiva comunal, me propuse un experimento etnográfico que consistía en hacer una comparación ciega entre interpretaciones paleográficas. El producto, una transcripción doble, se reproduce más adelante en los apéndices I y II. La primera transcripción fue hecha por uno de los historiadores campesinos más aficionados a la historia, un comunero quien ha ejercido muchos cargos en su ayllu 6 y también en la comunidad. Esta primera transcripción había sido preparada para el uso de la comunidad antes de mi llegada. La segunda es la que hice utilizando las técnicas que aprendí durante mi formación doctoral. A continuación, comentaré las discrepancias entre ambas versiones, para después estudiar la explicación que un experto local ofrece (Gushiken, 1993: 119). Termino comentando la importancia de su interpretación para la creación de una identidad poscolonial.

\footnotetext{
${ }^{6}$ Ayllu es una voz quechua que se refiere a un modo de organización social andina. El ayllu es un grupo de parientes que participa como un conjunto en el manejo de tierras y ganados pertenecientes al grupo, aa través del control laboral y de vínculos de reciprocidad entre sus miembros. Tiene un ancestro apical y dos linajes paralelos entre los cuales se forman parejas para matrimonios.
}

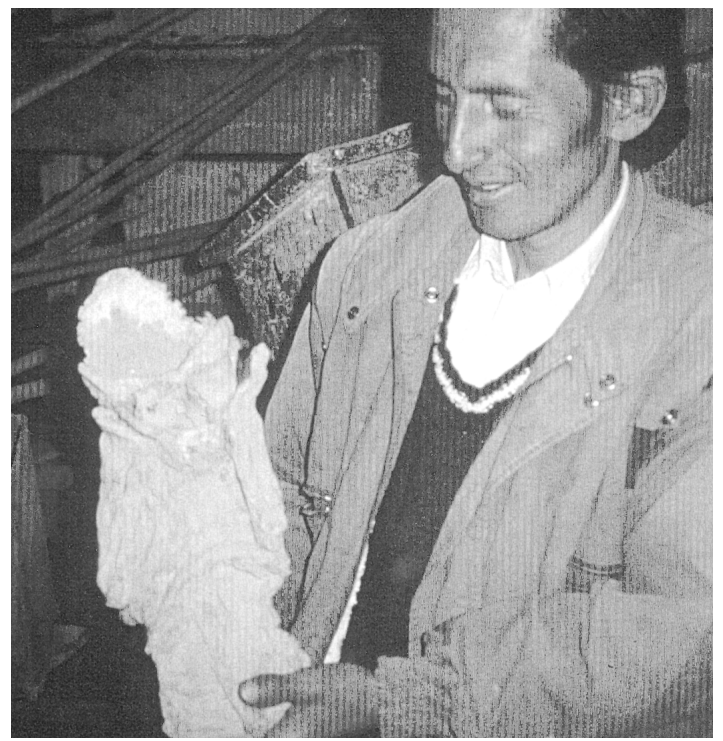

FIGURA 3: $s / t$; foto: Frank Salomon

\section{Transcripción por León Modesto Rojas Alberco}

El historiador aficionado y autor de la primera transcripción es León Modesto Rojas Alberco, nacido en 1947 y desde 1973 elegido varias veces a puestos de liderazgo dentro de su propio ayllu (Segunda Satafasca, segmento del ayllu Sat Pasca mencionado en la fuente quechua de 1608) y dentro de la comunidad. A pesar de ser hijo de un profesor de la escuela fiscal, Rojas tuvo que salir del centro educativo sin obtener su diploma. Después de una residencia corta y frustrante en Lima, ha pasado su vida casi exclusivamente dentro del ambiente campesino. Rojas se apasiona por la historia, sobre todo por la de Europa y de Asia, y lee toda la materia impresa que se le presente. En comparación con la escasez de libros en el pueblo durante casi toda su vida, ${ }^{7}$ su colección personal es amplia. Su interés por la historia se relaciona con su afiliación política con uno de los partidos de la Izquierda Unida. Durante su período de secretario de la comunidad, se dedicó voluntariamente a descifrar los documentos

\footnotetext{
${ }^{7}$ Gracias al esfuerzo del alcalde Roy Vilcayauri, esta escasez se alivió en 2000-2001 mediante la adquisición de una colección municipal que llena dos estantes.
} 
coloniales del archivo comunal, y poco a poco se volvió experto autodidacto en la paleografía. Ha compilado sus transcripciones en una serie de cuadernos personales, $y$ sigue asesorando a la comunidad en cuestiones de documentación. Si al momento de hacer el inventario anual de los enseres comunales en el archivo de la comunidad hay confusión — situación que se presenta casi todos los años- Rojas es la persona consultada para aclararlo. Sabe transcribir la escritura de los escribanos coloniales (incluso el procesal, estilo del que decía Cervantes que ni el diablo podía leerlo) con un nivel comparable al de los estudiantes doctorales con instrucción básica en paleografía. Hoy sigue siendo dedicado investigador por afición, y se levanta a las cuatro de la mañana para transcribir textos a luz de la vela antes de comenzar su trabajo en las chacras. ${ }^{8}$ Sus discursos elocuentes en las reuniones cívicas han hecho mucho para que sus ideas historiográficas figuren en la opinión pública. Sin embargo, la historia legendaria resumida a continuación es, en sus lineamientos fundamentales, una idea consensual y no creación propia de Rojas.

\section{CÓMO EL AUTO DE LOS MUERTOS SE DESARROLLA DENTRO DEL CONOCIMIENTO POPULAR}

Joanne Rappaport ha publicado un estudio innovador en el cual se explica la manera en que ciertos colombianos modernos dedicados a revitalizar su propia etnicidad pasto leen documentos coloniales (1994: 106-114). Rappaport argumenta que al movilizar las escrituras antiguas en apoyo de sus pretensiones legales, los campesinos encuentran dificultades debidas a la opacidad de la terminología legal colonial, y enfrentan tales retos con ciertas estrategias interpretativas características. Los párrafos que siguen describen las estrategias interpretativas de los tupicochanos, que se condicionan no sólo por las ideas que maneja la comunidad en cuanto al estilo "correcto" de lectura (Boyarin, 1993), sino también por ciertas

\footnotetext{
${ }^{8}$ Campos de cultivo.
}

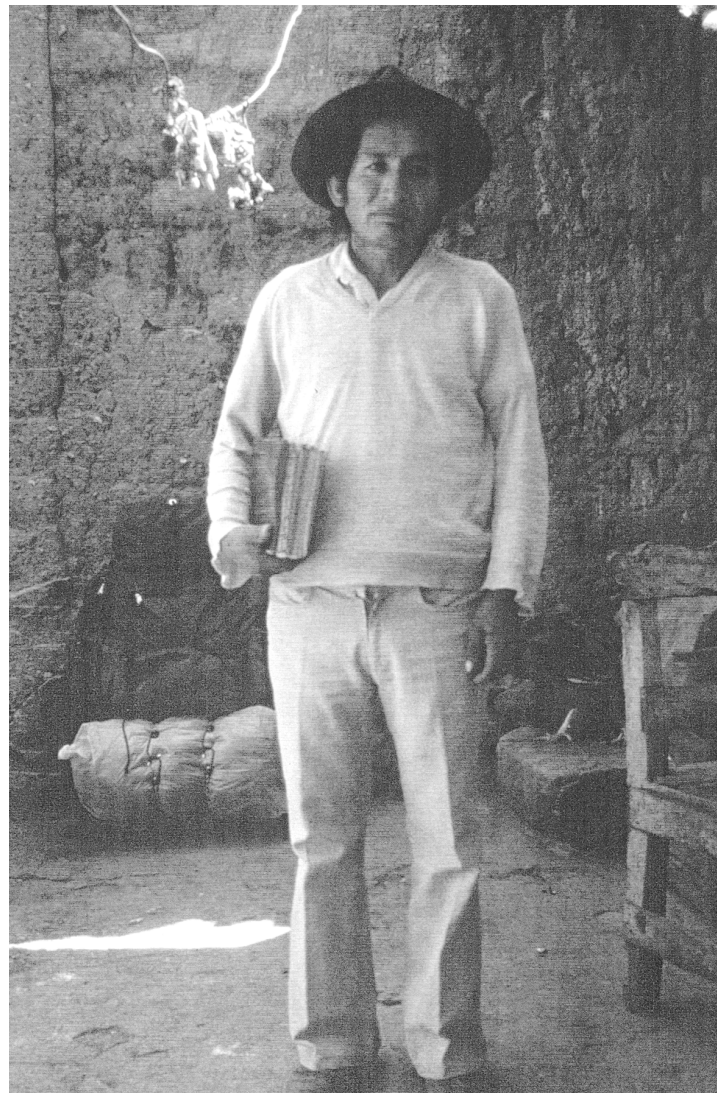

FIgURA 4: León Modesto Rojas Alberco; foto: Frank Salomon

nociones de historia general trasmitidas oralmente, y por la intención pragmática de la lectura al momento de realizarla (Howard-Malverde, 1994: 122).

Una noción de historia general que resulta consensual en toda la región y que forma el trasfondo interpretativo para Rojas Alberco, es la creencia que los restos óseos humanos que llenan las cuevas, abrigos y chaucallas resultaron de un suicidio "indio" masivo. El intento pragmático de las lecturas modernas en Tupicocha es, en primer lugar, el de proveer una doctrina de legitimidad en foros intracomunitarios, capaz de cimentar el apoyo público a los litigios sobre linderos y reclamos contra agencias del Estado, intereses comerciales, etcétera, que son endémicas en aquella región. Como se ha comentado arriba, la legitimidad implica la necesidad de ser a la vez autóctonos en cuanto al origen y la organización social, y 
"modernos" o "constitucionales" en la forma de manejar legalidades, presentándose como campesinado progresista. No obstante, esta función se desarrolla en permanente contacto con una tradición oral que incorpora modelos mucho más antiguos y globales de la identidad y del cambio. Estos modelos implícitos, que influyen igualmente en la interpretación, pueden explicarse trazando los detalles de la recepción moderna del texto antiguo. Mi interés no se centra en la veracidad de los documentos ni en sus interpretaciones, sino en ciertos atributos del diálogo entre presente y pasado. En especial me interesa saber cómo los lectores carentes de medios privilegiados para establecer lecturas autoritativas tales como las credenciales de abogado o de académico, o licenciado en paleografía ${ }^{9}$ crean una versión eficaz del pasado.

\section{Primera comparación entre las transcripciones: las normas y sus significados}

Al comenzar su período de secretario comunal en 1979, Rojas Alberco ya había visto transcripciones hechas por paleógrafos legales y entendía bien el estilo oficial. Sin embargo, escogió un método distinto. Rojas Alberco no buscó crear una transcripción, sino un facsímil del documento antiguo. Existe una discrepancia tácita en cuanto a cuáles son los elementos significativos de la escritura. Mientras los paleógrafos oficiales (como los historiadores) sólo consideran el "contenido", vale decir la sucesión de caracteres alfabéticos y su formato legal como significativos, los huarochiranos campesinos consideran que todo atributo físico del original tiene significado. Hasta los que no son muy letrados se interesan vivamente en detalles tales como el tamaño de la escritura, los adornos y rúbricas de las firmas, las huellas descoloridas que dejó la cera de los sellos virreinales, las formas de encuadernación en pergamino, ${ }^{10}$ etcétera. A su modo de ver, a me-

\footnotetext{
${ }^{9}$ En derecho peruano, los documentos antiguos presentados como recaudos de litigio tienen que ser transcritos por un paleógrafo autorizado por los tribunales.

${ }^{10}$ En muchas casas campesinas existe la costumbre de guardar los papeles de interés vital en paquetes hechos de cuero de cabra.
}

dida de que la nueva copia refleje con mayor fidelidad aquellos detalles, ésta comunica el "verdadero" contenido del original. Los huarochiranos describen la escritura colonial como mosaico (o con menos frecuencia como latín) y la consideran como código auténtico pero impenetrable. La tarea del paleógrafo popular es la de producir un artefacto que deje al lector moderno la sensación, no de leer palabras antiguas en letra moderna, sino de leer el mosaico mismo. La teoría implícita, entonces, interesa por sus implicaciones no-saussurianas: la escritura se imagina como impresión o fósil de un intercambio social total, y no como simulacro de una serie de fonemas codificados. Es imposible vertir el mosaico de un recipiente gráfico a otro desigual ( $v . g$., de manuscrito en pergamino a página mecanografiada) sin sacrificar el contenido, pues se postula un evento gráfico concretado de forma única en su primera manifestación física. La transcripción casera sí utiliza los grafemas en formas técnicamente distintas de las formas del mosaico (v.g., o minúscula cursiva cerrada abajo es reemplazada por la $o$ moderna cerrada arriba). No obstante, estos cambios funcionan como una instrumentalidad diseñada para funcionar subconscientemente, para que el lector sienta la presencia de un "original" de forma análoga a la reproducción de cuadros pintados mediante el fotograbado. El alfabeto modificado, tanto como la matriz reticulada de los puntos fotograbados, falsifica la superficie original con el propósito paradójico de suscitar en la mente del vidente una imagen fiel del original. De esta forma, la transcripción casera brinda al lector una participación imaginaria en el evento gráfico original. Su finalidad es distinta a la de la transcripción académica o legal, que busca exportar el "contenido" al evento moderno eliminando las "formas" difíciles.

\section{Una segunda comparación entre las dos transcripciones: lecturas divergentes}

Las partes del documento que representaron retos para Rojas lo fueron no sólo a causa de la escritura arcaica o descolorida o de los cambios ortográficos, sino también porque el texto se refiere a instituciones sociales extrañas 
al contexto moderno. En el Auto de los muertos, la dificultad principal fue el desconocimiento de los términos obsoletos revisita y retasa ${ }^{11}$ (letassa, en su transcripción). Esta dificultad hizo que el documento como un todo le resultara menos que transparente. En varios puntos específicos, la terminología obsoleta creó incertidumbres en busca de una interpretación.

Por supuesto, este problema no sólo aflige a los paleógrafos autodidactos; al tener dudas, todo paleógrafo se vale del contexto para escoger entre las interpretaciones posibles. En el caso del estilo procesal, el paleógrafo utiliza constantemente lecturas basadas en contexto, ya que la escritura abunda en ambigüedades al nivel de letras individuales y hasta de palabras enteras. Funcionó bien en su época solamente porque se aplicaba a una gama restringida de marcos genéricos, dentro de los cuales se proveía al lector una buena cantidad de frases formuláicas y redundancias. La diferencia entre las lecturas rurales y las académicas se arraiga en el hecho de que el campesino trae a la lectura un repertorio diferente de géneros conocidos y marcos conceptuales. En el caso del lector ria oral, de los ritos modernos, y de las preocupaciones pragmáticas dentro de la política influencian la selección entre las lecturas plausibles a primera vista.

En doce puntos o más, Rojas escogió una lectura distinta de lo que escogería un historiador. Los más significativos entre ellos son los siguientes:

\section{(Fs: Salomon; LMRA: Rojas)}

1. FS: "hedad de dies y ocho"

LMRA: "verdad de diciocho"

Comentario: Rojas supone que el autor está preocupado por la rapacidad de las autoridades españolas, a quienes se les sospecha de la imposición de tributos a personas que no fueran "verdaderamente" de edad tributaria.

2. FS: "Dando rason pormenor de las cantidades que ubiere cobrado"

${ }^{11}$ El primer término se refiere a las inspecciones para actualizar listas de tributarios. El segundo se refiere al ajuste de las tasas impuestas.
LMRA: "dando su soporte manos de los castigos dados"

Comentario: Rojas tomó lo que le parecía un hecho creíble dentro del contexto - la "mano" española levantada en "castigo" a los tributarios - como suficiente evidencia para respaldar una lectura con sintaxis irregular. (Los expedientes legales con frecuencia incluyen largas cadenas de cláusulas u oraciones ambiguamente articuladas. Por lo tanto, todo paleógrafo tolera la anomalía sintáctica de vez en cuando.)

3. FS: "Que yndios an muerto despues de la ultima retasa" y

"Que yndios an muerto desde la ultima retassa"

LMRA: "q' Indios han muerto de pena de la ultima letassa" (para ambas frases)

Comentario: Hay discrepancias paralelas en las transcripciones de las dos frases originales. Como en los ejemplos anteriores, las experiencias contemporáneas con problemas impositivos y la tradición oral acerca de los opresores españoles (siendo esta última reforzada por los textos escolares) motivan la lectura dada por Rojas: que las retasas hicieron a los indios morirse de pena.

\section{FS: "en cuya conformidad" \\ LMRA: "en la ya contaminidad"}

Comentario: La muerte y la contaminación tienen una fuerte asociación en toda la región andina. Se cree que hasta los muertos enterrados por mucho tiempo siguen despidiendo una sustancia nociva (el antimonio o lurya; según Abercrombie y Dillon, 1988). La palabra "contaminación”, difundidísima en el periodismo, sirve como nexo semántico entre el antiguo concepto del antimonio y el concepto moderno de venenos ambientales. Esta afinidad dio el marco para detectar en el texto las consecuencias esperadas de las "muertes" anteriormente mencionadas.

5. FS: "alcalde de mayordomías"

LMra: "Alcalde Mayor, de Minas"

Comentario: El pueblo de Rojas tiene unas minas pequeñas, y minas más importantes existen a poca distancia. 
Dentro de la tradición oral, las minas se asocian, no sin razón, con trabajos forzados. Aunque Rojas tiene conocimiento de las mayordomías, percibió un marco interpretativo más convincente al contemplar el vínculo entre la tasación española y el trabajo forzado.

El examen detallado de la transcripción revela, en fin, que ante los ojos de un paleógrafo autodidacto, el Auto de los muertos registró una situación en la cual los abusos tributarios (exigir tributos de menores de edad, forzar a los campesinos a trabajar en las minas e infligir castigos crueles) habían ocasionado la muerte de muchos. Sus muertes, según Rojas, contaminaron el ambiente de la zona. La tradición oral llena los vacíos en este cuadro.

\section{Cuando Huarochirí se convirtió en osario: la explicación oral del Auto de los muertos dada por el paleógrafo local}

Para Rojas y para muchos que acreditan sus interpretaciones, esta pequeña muestra del papeleo administrativo y la instancia de violencia y resistencia que se conmemora en ella, establecen una base para la identidad colectiva. Dentro de la historiografía folclórica que él transmite a sus vecinos, representa nada menos que el indicio de una transformación social total. En 1994, Rojas me explicó que "los muertos" mencionados en el título del Auto de los muertos son los gentiles; esto es, los muertos momificados y los esqueletos antiguos que se encuentran en el campo. La siguiente transcripción de sus palabras se hizo verbatim y conserva algunas irregularidades gramaticales.

[El Auto de los Muertos] significa que han presentado un escrito el procurador y los principales de los pueblos de indios de diferentes huarangas ${ }^{12} \ldots$ porque en aquellos años, según reza el documento este, que ya todo el territorio de Huarochirí se encontraba en una horrible putrefacción de seres humanos que se diseminaban, se encontraban por aquí y por acá. Ya no se podía soportar los olores. Pero

\footnotetext{
${ }^{12}$ Huaranga: categoría de mil tributarios según el censo inca. La categoría se seguía usando en la administración durante aproximadamente el primer siglo de la época colonial.
}

¿por qué los muertos han muerto?, yo me preguntaba. Es porque, primer lugar, por los trabajos forzados que hacían los españoles contra los indios. Y después, por el tributo exigido que también se daba a los indios. Otro, del según dicen mis antiguos compoblanos, el de no querer ellos comer la sal. ${ }^{13} \mathrm{Ni}$ querer probar la sal. Eso fue lo que a ellos llevó a matarse entre ellos. O sea, la muerte, o sea, el auto de la muerte significa que ellos mismos se han muerto, no fueron los españoles quienes los han matado, sino que ellos mismos. Ya de tanto fue, que un principal de la comunidad de Santiago creo que es... dio el primer grito que se abula todo ese abuso que había. Por eso es que [el] título auto de los muertos trata cómo se puede evitar todo eso... ellos mismos se ahorcaban. No se peleaban entre ellos. Seguramente se han de decidir que entre ellos a que al uno, al otro, y así sucesivamente para no sufrir más este castigo tan malévolo que hubo de los españoles...con las sogas al cuello.

En 1997, a petición mía, volvió sobre el mismo tema:

[Los gentiles momificados y los huesos en tumbas antiguas son naturales quienes] simplemente han renunciado de ser esclavos de los españoles para determinarse ellos mismos. Porque el tributo y el azar, y el trabajo forzado, decidieron en matarse. Suicidarse. Porque el auto de los muertos dice, por no atender a comer sal, mejor dicho, a seguir con la sal, a seguir con trabajo forzado y a seguir en los tributos tan fuertes, es donde ellos determinaron exterminarse. $Y$ al exterminio que hubo, Ud. sabe, que una persona se vuelve muy fea cuando está muerta ya. Cuando el cuerpo se descompone. ¡Horrible! Ya había mucha plaga ya, porque había contaminado el ambiente. Entonces el Corregidor de Huarochirí ordenó a que se suspende el tributo y el trabajo forzado. Ahí es que un sangallayino ${ }^{14}$ se presentó este documento porque ya no se podía vivir ya en todo Huarochirí. O sea este era un indio sangallayino. No era tampoco un español, un Corregidor ni un capataz. Que también quiso sublevarse o pidió satisfacción para que eso, no haiga eso. Porque estaba ya demasiado contaminado todo el ambiente. Y se suspendió. Y al suspenderse se echó las campanas a vuelo se dice, o sea se repicaron las campanas en todo Huarochirí cuando ya se suspendió eso... A la verdad que ellos habían ganado la batalla crucial en que ellos vivían.

\footnotetext{
${ }^{13}$ Esta frase se refiere al monopolio estatal de la sal, recordado en memoria popular como un impuesto intolerable. Continuó durante la época republicana y hasta 2001 existió el local del estanco de sal. ${ }^{14}$ Sangallaya es un pueblo cerca a la capital provincial de Huarochirí.
} 


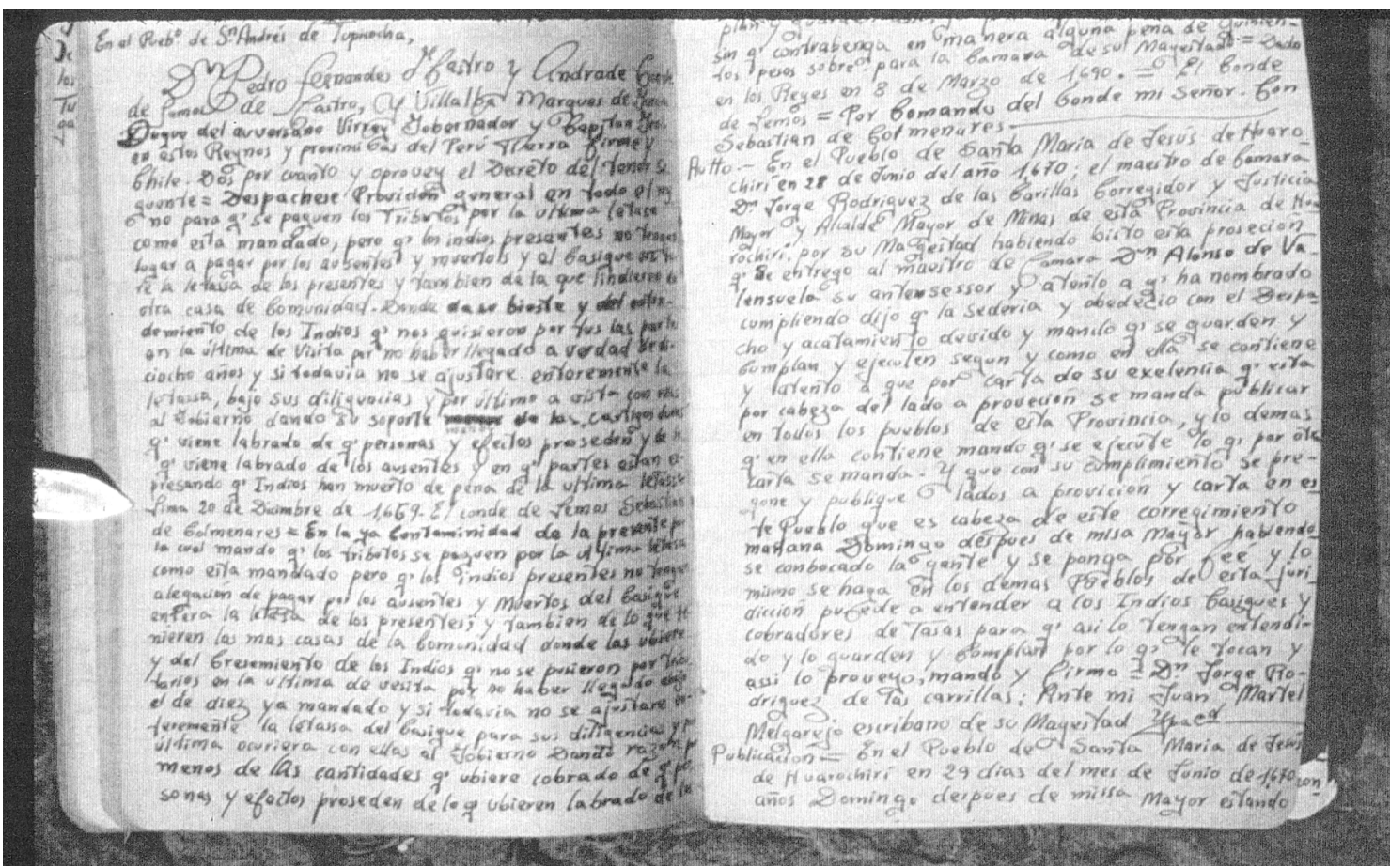

FIGURA 5: Auto de los Muertos; foto: Frank Salomon

[Fs: Si se murieron suicidándose, ¿̨por qué sus huesos están recogidos en las chaucallas y no esparcidos en varios sitios?]

Se han colgado de las peñas. Después se han trasladado también, porque también hay lugares donde no hay peñas, nada, pero se encuentra cantidad de huesos. Una enorme cantidad. Como de Collanche, ${ }^{15}$ por ejemplo, son tumbas donde han, este [vacilación] parece de los millonarios, de los curacas, de los caciques, de los principales que se los llamaron ahora; de ellos han sido enterrado en fosas así, pero no adentro en la tierra como ahora se hace, sino con piedras lajas se han hecho unas chullpas. Unos chullpas. Y no están enterrados solos, sino ahí están todas sus pertenencias, sus huacos, ${ }^{16}$ vasijas, como quien quiere decir que en la otra vida se va a seguir viviendo. [Risa.]

15 Un sitio arqueológico local con entierros, que no ha sido estudiado científicamente.

${ }^{16}$ Huaco significa artefacto o entierro precolombino, frecuentemente de cerámica.
[FS: ¿Y después del repique de las campanas?]

Sí hubo [el dominio español] pero en menor grado de ejecución de su castigo.

[FS: ¿Los sobrevivientes del gran suicidio, son los ancestros de los que viven ahora?]

Muy poco. Se acabó casi. Se acabaron. Porque no encuentro apellidos de esos años ahora.

El concepto del pueblo como herencia legada a los actuales habitantes por indígenas convertidos en ancestros míticos a través del suicidio ha entrado en la corriente de la tradición oral como se presenta en contextos cívicos. Aún más: debido a esta hecatombe, los aborígenes dejaron la tierra en condición mejorada, ya que con sus muertes redimieron a los campesinos del trabajo forzado y de la opresión colonial.

¿Hasta qué grado se generaliza y acepta esta interpretación? Rojas Alberco ha llegado a influir bastante en el 
discurso público, así como en la escritura de los documentos internos de la comunidad. Jamás oí a nadie cuestionar explícitamente la versión expuesta arriba. Al contrario, oí varias versiones orales similares, aunque menos complejas, en pueblos por toda la provincia de Huarochirí. Sin embargo, esta idea del pasado no es la única en juego. Desde la escuela se propaga una narrativa más convencional. La historiografía folclórica pasa por corrientes casi completamente separadas de la educación oficial. Aunque en teoría el currículum prescrito en Lima deja cierto espacio abierto a temas de interés local, los profesores se quejan de contar con pocos materiales pedagógicos orientados hacia lo local. Algunos profesores respetan el conocimiento local, y hasta lo recopilan, pero la mayoría lo trata como obsoleto o supersticioso. Si el centro educativo abarca las tradiciones, las abarca en la categoría del "folclor". Los moradores locales valoran altamente el conocimiento escolarizado, y en efecto hay pocos analfabetos. Sin embargo, al igual que casi todos los pobladores rurales en los países andinos, los campesinos tupicochanos aceptan como parte de la normalidad el abismo que separa el conocimiento "educado" de las verdades particulares y propias pertenecientes a cada pueblo.

Cualquier persona que pretende posicionar su discurso más cerca del polo "nacional" y oficial, por lo tanto, se inclina a apoyarse en ciertas "monografías" semipublicadas (con frecuencia fotocopiadas). Éstas reúnen una miscelánea de saberes derivados de las ciencias aplicadas y de la estadística socioeconómica. La mayoría de aquellas monografías se crearon como tesis de grado en las universidades estatales que prepararon profesores, y reflejan las sucesivas ideologías politicas que han tenido sus momentos de supremacía en el medio pedagógico: el desarrollismo de los años 1950, el marxismo dogmático de los 1980, y hoy en día el neoliberalismo. Tomadas en conjunto con ciertas obras clásicas de la historia regional como la de Sotelo (1942), y con los álbumes cívicos publicados ocasionalmente por las asociaciones de excampesinos residentes en Lima, dichas tesis tienden a canonizarse localmente como vehículos del saber histórico "educado". Se conservan en la escuela, al extremo del pueblo opuesto al Local Comunal y sus archivos coloniales. La oposición entre historia canónica y vernácula no se dra- matiza enfrentando una a otra empíricamente, ni se disputan. La contestación se da mediante discursos alternativos a nivel de liderazgo en diferentes contextos $-\mathrm{y}$ a veces hasta la misma persona presenta discursos diferentes ante públicos distintos.

\section{CONCLUSIONES: SOBRE LAS INVESTIGACIONES COLABORATIVAS, LA MEMORIA DE LA COLONIZACIÓN, Y LA IDENTIDAD CULTURAL}

El experimento etnohistórico descrito explora una relación de paridad entre el autor y el investigador campesino. Se comparte la simpatía moral expresada por Price (1990: XIX) al contemplar la narrativa local que cuestiona el presente, y converge con las conclusiones de Rappaport al analizar las formas de controlar el pasado denominado como "útil". Este experimento corrobora la aserción de Gudeman y Rivera (1995: 245) de que el trabajo de campo antropológico se lleva a cabo "dentro de una comunidad de investigadores" mucho antes de mandarse "a casa” para comenzar su periplo por el mundo académico. El investigador de campo documenta por necesidad el constante proceso autointerrogativo de una sociedad, presenciando sus diálogos internos. Por lo tanto, el investigador llega a ser no solamente testigo, sino también partícipe en "conversaciones" de las cuales su propia narrativa jamás podrá independizarse.

Si un grupo contiene personas notablemente dedicadas a la reflexión sobre tales "conversaciones", entonces aquellas personas no deben considerarse como "intelectuales campesinos" ("orgánicos", "indígenas", etcétera) sino como intelectuales colegas. Desde este punto de vista, las discrepancias entre el resultado obtenido por un investigador extranjero y por un intelectual local no tienen que evaluarse meramente como la distancia interesante pero quizás imponderable entre esquemas internos a un grupo cultural, ni como margen de error debido al peso de los intereses creados, aunque éstas también son preocupaciones inevitables. Algunas de las discrepancias conciernen a la perspectiva, y son similares a desacuerdos académicos entre investigadores que manejan perspec- 
tivas parciales distintas, o muestras inconmensurables. Sin embargo, las diferencias de perspectiva y de distancia entre trasfondos axiomáticos suelen ser mayores. Si los resultados locales parecen extraños, no hay por qué presumir que son menos fundamentados en la experiencia. A pesar de su carga de ideología local y de su informalidad metodológica, un pasado vernáculo podría llevarnos a reevaluar, de manera sustancial, aspectos de la historia supuestamente conocida. Si no permitimos que la etnohistoria strictu sensu rete a la historiografía académica, ésta resulta ser un mero gueto.

Los comentarios finales se dirigen, en primer lugar, a la importancia del motivo del "suicidio étnico" dentro de la ideología local, y en segundo lugar al reto histórico implícito en el concepto local de la época colonial. Dentro de la comprensión popular de la historia, y a diferencia de lo que se aprende en la escuela, la hecatombe voluntaria de los indios - y no la conquista españolamarcó el fin de la época propiamente indígena en el campo huarochirano. Los habitantes interpretan las numerosas ruinas arqueológicas alrededor del pueblo como sitios donde los "indios" se ahorcaron o se enterraron vivos en grupos masivos. Pero en contraste con los crímenes de los españoles, que también se recuerdan, el gran suicidio se imagina como victoria moral, porque convirtió a Huarochirí en tierra de hombres y mujeres eternamente libres. Las familias modernas de la zona no se consideran descendientes directos de aquellos antiguos moradores. En las muchas ocasiones en que he preguntado si aún existen "indígenas" o "indios" en Huarochirí, la respuesta ha sido unánime: "Ni uno." Al mismo tiempo, las familias locales se consideran como los herederos de los antiguos. ${ }^{17}$ Los vivos deben a los antepasados suicidados no sólo su acceso a las tierras, sino también la emancipación cívica, y estos dones merecen una reverencia eterna.

\footnotetext{
17 ¿Faltará un vínculo lógico? Cuando han sido preguntados si sus propios ancestros podrían haber inmigrado de otros lugares, los tupicochanos admiten la posibilidad en principio. Pero los ejemplos que usan pretenden demostrar que los otros pueblos o ayllus en la zona tienen orígenes atípicos por vía de inmigración. Por ejemplo, opinan que el ayllu Cacarima tiene raíces en la zona peruana de Huancayo, y que algunos linajes del vecino pueblo de Sunicancha tienen por fundadores ancestros italianos.
}

Esta versión del pasado demuestra originalidad y autosuficiencia intelectual. Constituye una solución a los enigmas de la discontinuidad histórica, independientemente de los modelos hegemónicos proyectados por las escuelas, la iglesia, y las organizaciones no gubernamentales. Pero para dar a este modelo su valor merecido hay que seguir adelante en dos direcciones. Primero, resulta interesante pensar en la comunidad campesina como una colectividad con funciones investigativas. Tupicocha continuamente estudia sus propios registros escritos, principalmente para fines administrativos inmediatos, pero a veces para fines más estratégicos. En la labor investigativa, practica una metodología autónoma, ya que busca explicar los hechos desde un punto de vista local, dando prioridad a las evidencias tomadas de fuentes locales ( $v . g$., observaciones sobre estructuras y características geográficas tanto como documentos; véase Rappaport, 1990, 1994), y a la elaboración de hipótesis compatibles con las tradiciones vernáculas que sean a la vez útiles al enfrentar las relaciones con el estado y con comunidades adyacentes (Krupat, 1992). Los "intelectuales campesinos" que se dedican al autoestudio histórico y, en otros contextos, a la autoetnografía, al hacerlo realizan el quehacer intelectual normal y subestimado de la existencia comunal. Aunque es verdad que algunos, como Rojas, han funcionado como figuras opositoras, el énfasis dentro de la tradición gramsciana en las relaciones oposicionales y colaborativas con los agentes "dominantes" (Ranger, 1993) y la supuesta dependencia del proceso intelectual entre los pobres en el diálogo con las elites y sus adversarios oculta la medida en que el autoestudio forma una parte de la infraestructura interna y permanente de la sociedad rural.

En segundo lugar, conviene apreciar que debemos tomar en serio el panorama histórico conceptualizado desde el pueblo rural, por mucho que diste del paradigma académico sobre colonialismo y "etnicidad" andina. Sería un error descontar sus conclusiones como errores pintorescos, aun cuando sus argumentos involucren errores de paleografía o de cronología. Con frecuencia, los estudios académicos sobre el impacto del colonialismo en las identidades rurales muchas veces han acentuado la implantación de la "indianidad" como un atributo de la competencia social, rutinaria e inevitable (Salomon y 
Guevara, 1994; Stern, 1982; Spalding, 1984; Lavallée, 1982). Las investigaciones publicadas sobre la historia oral se inclinan a acentuar las narrativas sobre la época colonial (y en especial las que repiten el interminablemente discutido tema del Inkarrí; véase Burga, 1988; Flores Galindo, 1987; Ortiz, 1973) como si fueran representativas de una época de opresión soportable aliviada solamente por esperanzas milenarias.

Los huarochiranos recuerdan la época colonial intermedia de otra manera. No niegan el martirio de los "indios" ni subestiman los males del viejo régimen. $\mathrm{Al}$ contrario, lo afirman más que los mismos historiadores, al convertir la totalidad del registro arqueológico en su monumento. Pero consideran también que la era colonial fue el período cuando los antepasados emergieron de la esclavitud del período "Inka-Habsburgo" (Platt, 1997: 222). (La época bolivariana, principal enfoque de la historia emancipacionista aprendida por todo peruano en la escuela, tiene menor presencia en la historiografía vernácula.) Desde el punto de vista del pueblo moderno, la colonia no es ya la época en que las diversas poblaciones andinas se convirtieron en "la gente llamada indios", como lo fue $c a$. 1608 , cuando un huarochirano desconocido escribió aquellas palabras en el prefacio al famoso manuscrito quechua de Huarochirí. Al contrario, el virreinato fue el período cuando se dejó atrás el modo de vida prehispánico e "indio". En el virreinato, la cultura reconocida como "la nuestra" - la cultura autogestionaria que subyace la democracia pueblerina - comenzó a existir.

¿Habrá algo de realismo en esto? En efecto, no se sabe precisamente cuándo los huarochiranos dejaron de aceptar la categoría de "indios", ni se sabe cuándo quedó cristalizado el estilo de vida étnicamente ambiguo que ahora practican. Tampoco se ha esclarecido en qué medida los pobladores no originarios remplazaron a los de ascendencia prehispánica local durante los períodos en que la población indígena estaba en declive. Igualmente desconocidas son las fechas en las cuales el pueblo desarrolló su impresionante sistema de democracia comunal. En vista de todo esto, la idea de que la autogestión y la autodefinición en términos de personas libres nacieron durante la época colonial no parece tan inevitable- mente equivocada. De hecho, puede ser una pista historiográfica importante.

El Auto de los muertos, entonces, puede verse como emblema de una identidad pública "auténtica" pero no étnica, y de una ideología que fundamenta la dignidad de la ciudadanía en historia endógena. Aunque el idioma mitohistórico nos parezca exótico, y la periodización sorprendente, el razonamiento no resulta incompatible con la historiografía de los años noventa, que buscó trazar los orígenes de las identidades del "peruano" y del "ciudadano" a través de sucesos y movimientos regionales propios al campesinado ( $v . g$., en una literatura en efervescencia, como Mallon, 1993; o Thurner, 1997).

Sin embargo, la relación entre cultura, historia y estructura en Tupicocha sigue presentando problemas provocativos. La mentalidad arriba descrita, aparentemente opuesta en extremo al indigenismo, ha permitido que la comunidad retenga estructuras culturales "andinas" y aun prehispánicas. Entre ellas figura el gobierno constituido por ayllus confederados — un isomorfo aparentemente cercano al patrón de gobierno prehispánico. Tales estructuras fueron abandonadas hace tiempo por la mayoría de las colectividades más claramente "andinas" o más explícitamente "étnicas". Estas son algunas de las realidades etnohistóricas que la etnografía moderna todavía intenta alcanzar.

\section{APÉNDICE I \\ Transcripción paleográfica del Auto de los muertos por León Modesto Rojas Alberco}

El Auto de los Muertos ${ }^{18}$

En el Puebo de Sn Andrés de Tupicocha,

$D^{n}$ Pedro fernandes de Castro y Andrade Conde de Lemos de Castro y Villalba Marques de Jarcia Duque del

\footnotetext{
18 APLMRA / SAT ¿1979? Transcripción hecha por León Modesto Rojas Alberco $c$. 1978, en su cuaderno particular núm. 2, p. non núm. 80-82, de ACCT / SAT fólder 26: 1670 [Provisión real de] Don Pedro Fernández de Castro y Andrade Conde de Lemos Castro, Andrade y Billalba... birrey... [sobre tributos de Huarochirí; 14 julio 1670].
} 
Aversano Virrey Gobernador y Capitan Genl. en estos Reynos y provincias del Perú Tierra firme y Chile. Doi por cuanto yo provey el Decreto del tenor Siguiente == Despachese Provicion general en todo el reyno para q' se paguen los Tributos por la ultima letasa como esta mandado, pero q' los indios presentes no tengan lugar a pagar por los ausentes y muertos ye el Casique en tere la tassa de los presentes y tambien de la que lindieren de otra casa de Comunidad. Donde da su bieste y del entendemiento de los Indios q' nos quisieron por tus las partes en la última de Visita por no haber llegado a verdad de diciocho años y se todavia no se ajustare enteremente la letassa, bajo sus diligencias, y por último a vista con ellas el Gobierno dando su soporte [tarjado ilegible; infraescrito: manos] de las castigos dados q' viene labrado de a' personas y efectos proseden y de lo q' viene labrado de los ausente y en q' partes estan expresando q' Indios han muerto de pena de la ultima letassa de Lima 20 de Diciembre de 1669. El conde de Lemos Sebastian de Colmenares = En la ya contaminidad de la presente por la cual mando q' los tributos se paguen por la ultima letasa como esta mandado pero q' los indios presentes no tengan alegación de pagar por los ausentes y Muertos del Casique entera la letasa de los presentes, y tambien de lo que teniereren las mas casas de la Comunidad donde las ubiere y del Cresemiento de los Indios q' no se pusieron por tributarios en la ultima de vesita por no haber llegado abajo de diez ya mandado y si todavia no se ajustare enteremente la letassa del Casique para sus diligencias y por ultima ocuriera con ellas al Gobierno Dando razon por menos de las cantidades q' ubiere cobrado de q' personas y efectos proseden de lo que q' ubieren labrado de los ausentes y en q' partes estan expresado q' indios han muertos de pena de la ultima letasa y el Corregidor de la Provincia de Huarochirí; cera q’ el casique o casiques de los Repartimientos de su Jurisdicción lo cumplan y guarden assi, y el por lo q' le toca. Lo ejecutara sin q' contrabenga en manera alguna pena de Quinientos pesos sobre para la Camara de su Magestad $=$ Dado en los Reyes en 8 de Marzo de 1,690 $[s i c] .=$ El Conde de Lemos $=$ Por Comando del Conde mi señor. Con Sebastian de Colmenares
autTo -- En el pueblo de Santa Maria de Jesús de Huarochirí en 28 de Junio del año 1,670; el maestro de Camara $\mathrm{D}^{\mathrm{n}}$ Jorge Rodriguez de las barillas Corregidor y Justicia Mayor y Alcalde Mayor, de Minas de esta Provincia de Huarochirí, por su Magestad habiendo bisto esta prosecion q' se entrego al maestro de Camara $\mathrm{D}^{\mathrm{n}}$ Alonso de Valensuela su antesessor y atento a q' ha nombrado cumpliendo dijo q' la sederia y obedecio con el Despacho y acatamiento devido y mando q' se guarden y cumplan y ejecuten segun y como en ella se contiene y atento a que por carta de su exelencia q' esta por cabeza del lado a proveción se manda publicar en todos los pueblos de esta Provincia, y lo demas q' en ella contiene mando q' se ejecute lo q' por otra carta se manda. Y que con su cumplimiento se pregone y publique ${ }^{19}$ lados a provición y carta en este Pueblo que es cabeza de este corregimiento mañana Domingo despues de misa mayor habiendose conbocado la gente y se ponga por feé y lo mismo se haga en los demas Pueblos de esta juridicción puede a entender a los Indios Casiques y cobradores de Tasas para q' asi lo tengan entendido y lo guarden y cumplan por lo q' le tocan y assi lo proueyo, mando y firmo $==D^{\mathrm{n}}$ Jorge Rodriguez de las carrillas; Ante mi Juan Martel Melgarejo escribano de su Magestad Ypaed [sic]

publicación En el Pueblo de Santa María de Jesús de Huarochirí en 29 dias del mes de Junio de 1670 años Domingo despues de missa mayor estando en la Plaza Pública de este dicho Pueblo y haviendo mucho; Converso de gente por los de Pedro Culcaya, Indio pregonero. Se pregono y se publico la provición contenidamente segun y como en ella se contiene y el auto de su obedecimiento en altas boces y despues de

\footnotetext{
${ }^{19}$ Aquí se encuentra un símbolo que consiste en una espiral en el sentido de las agujas del reloj.
} 
hacer publicado por interpretacion de $\mathrm{D}^{\mathrm{n}}$ Diego Comba Julca alcalde Ordinario de este otro Pueblo y por los de otro pregonero se dio a entender, a los Indios en la lengua Matterna ssiendo testigos Feliciano de Escobar Escribano Rl Dn Pedro de Carbajal y Salvador Urquisa = Juan Martel Melgarejo Escribano de su Magestad y Público----- Concuerda con su original q' queda en el archivo del papel de esta Provincia de Huarchirí [sic] a que me refiero y para q' de ello conste de la parte de los Indios del Pueblo de $S^{n}$ Andrés de Tupicocha del presente en el Pueblo de Huarochirí en 14 de Julio del ano 1670 [large letters sic].

[imitación de rúbricas]

Y En fee deello $D^{\mathrm{n}}$ cedros [rúbrica]

En Ante Mi $\mathrm{D}^{\mathrm{n}}$ Verde

$\mathrm{Ju}^{\circ}$ Martel Melgarejo Escro pub

Es Copia Fiel de su original q' se trascribe para sus demas fines de la q' doy fé en Tupicocha a los 8 dias del año 1979. Ex-secretario de la Comunidad. Firmado Febrero: [sic, blan]

León M. Rojas A. [rúbrica]

\section{APÉNDICE 2}

\section{Transcripción paleográfica del Auto de los muertos por Frank Salomon 20}

Don Pedro Fernández de Castro y Andrade Conde de Lemos Castro, Andrade y Billalba Marques de Jarcia

\footnotetext{
20 [Transcripción de] ACCT / SAT fólder 26, 1670. [Provisión real de] Don Pedro Fernández de Castro y Andrade Conde de Lemos... birrey... [sobre tributos de Huarochirí; 14 julio 1670]. Transcripción en Cuaderno de Frank Salomon, 95-03, p. 47-51.]
}

Duque del [Tavirsano?] birrey y governador y capitan general en estos Reynos y provincias de Peru tierra firme y Chile etc. Por quanto yo provey el decreto del tenor siguiente[...]

Despachese provisión general en todo el Reyno para que se paguen los tributos por la ultima tassa como esta mandado, pero que los yndios que [roto]sentes no tengan [obligación de?] pagar por los ausentes y muertos

[Margen izquierda superior:] para el pueblo de S Andres de Tupicocha

y el cacique entere la retassa de los presentes. y tambien de lo que rindieren las chacras de comunidad. donde las ubiere y de cresimiento de los indios que nase pusieron por tributarios en la ultima revisita por no aver llegado a la hedad de dies y ocho años y si todavia no se ajustase enteramente la Retassa haga sus diligencias / y por ultimo ocurra con ellas al govierno dando rason pormenor de las cantidades que ubiere cobrado de que personas y fechas proseden y de lo que ubiere cobrado de los ausentes e en que partes estan. expresando que yndios an muerto despues de la ultima retasa [hecha?] veynte de dissiembre de mil y seyssyentos y sesenta y nuebe el conde de lemos. Sebastian de Colmenares. $=$ en cuya conformidad [roto] di la presente por la qual mando. Que los tributarios se paguen por la ultima retassa como esta mandado pero que los yndios presentes no tengan obligacion de pagar por los ausentes ny muertos y el cassique enterera la retassa de los presentes. y tanbien de lo que rindieren las chacaras de la comunidad en donde las ubieren y del cresimiento de los yndios que no pusieron por tributarios en la ultima revisita. por no auer llegado a hedad de dies y ocho años. y si todabia no se ajustare enteramente la Retassa dicho casique hara sus diligencias. y por ultimo ocurrir con ellos al govierno. dando rrason por menor de la cantidad de que ubiere cobrado de que personas y efetos proceden y de lo que ubiere cobrado de los ausentes. y en que partes estan expresando [roto] que yndios an muerto desde la ultima retassa y el corregidor de la provincia de guarochiri ara que el casique o casiques 
de los Repartimientos de su jurisdision lo cumplen y guarden assi, y el por lo que le toca lo executara sin que contrabenga en manera alguna pena de quinientos pesos de oro para la camara de su magestad, fecha en los Reyes en ocho de marzo de mil y seiscientos y setenta años. $==$ el conde de lemos. $==$ Por $\mathrm{m}[\mathrm{an}$ ?] dado del conde mi señor. Don Sebastián de Colmenares.

\section{[Margen:] Auto}

En el pueblo de Santa Maria Jesús de guarochiri en beynte y ocho de junio de mil y seyscientos y setenta años, el maestro de canpo don Jorge rodrigues de las barrillas. corregidor y justicia mayor y alcalde de mayordomías de esta [roto] prouincia de guarochiri por su magestad haviendo visto esta provission que le entrego el maestro de campo don Alonso de Balensuela su antessessor y atento a que no se ha dado cumplimiento Dixo que la obedecia y obedesio con el respeto y acatamiento devido. y mando que se guarde cumpla y execute segun y como en ella se contiene y atento a que por carta de su ex[celenci]a que esta por cabesa de la dicha provission. se manda publicar en todos los pueblos de esta provincia. y lo demas que en ella se contiene mando que se execute lo que por dicha carta se manda. Y que en su cumplimiento se pregone y publique la dicha provision y carta en este pueblo que es la cabesa de este corregimiento mañana Domingo despues de missa mayor aviendo conbocado la jente y se ponga por fee. y lo mismo hagan en los demas pueblos. de esta jurisdision. y se de a entender a los yndios casiques y cobradores de tassas. para que ansi lo tengan entendido. y lo guarden y cumplan por lo que le tocan y asi lo proueyo - mando y firmo $==$ Don jorge rodriguez de las barrillas -- Ante $\mathrm{mi}$ Juan martel melgarejo escribano de su majestad y $\mathrm{p}[\mathrm{ubli}] \mathrm{co}$

\section{[Margen] Publicacion}

En este pueblo de santa maria de Jesus de guarochiri, en veynte y nueve dias del mes de junio de mil y seyscientos y setenta años, Domingo despues de missa mayor estando en la plassa publica deste pueblo y aciendo mucho cursso de jente por bos de pedro calcaya yndio pregonero a pregones y publico -- la provission [roto] contenido en este segun y como en ella contiene y el auto de obedecimiento, en altas boses. $y$ despues de auer publicado. por ynterpretacion de Don Diego Carbajulca alcalde ordinario de este dicho pueblo y por bos del dicho pregonero se dio a entender a los yndios en la lengua materna ${ }^{21}$ siendo testigos sebastian de escobar escribano de [roto] y don pedro de carbajal y salvador urquissa $==$ juan martel melgarejo escribano de su majestad y publico.

conquerda con su original que queda en el archivo de papeles de esta provincia de guarochiri la que me afirmo. y para que de ello conste de la parte de los yndios del pueblo de san andres de tupicocha di el presente en el pueblo de guarochiri en catorse de julio de mil y seiscientos setenta. en fee dello [firmas]

\section{Referencias bibliográficas}

\section{Manuscritos inéditos}

ACCT/SAT Folder 26, Archivo de la Comunidad Campesina de San Andrés de Tupicocha, 1670 [Provisión real de] Don Pedro Fernández de Castro y Andrade Conde de Lemos Castro, Andrade y Billalba... birrey... [sobre tributos de Huarochirí; 14 julio 1670].

APLMRA/SAT Cuaderno 2, [Transcripcion hecha por León Modesto Rojas Alberco, $c a .1978$, en su cuaderno particular núm. 2, p. non núm. 80-82, de ACCT/SAT Fólder 26:22 1670]: [Provisión real de] Don Pedro Fernández de Castro y Andrade Conde de Lemos Castro, Andrade y Billalba... birrey... [sobre tributos de Huarochirí; 14 julio 1670], 1979.

Martínez Chuquizana, T.A, Descripción geográfica del distrito de San Andrés de Tupicocha, manuscrito inédito, 1996.

\footnotetext{
${ }^{21}$ Esta frase normalmente significa un idioma regional, no el quechua. El quechua era descrito por los funcionarios como lengua general o lengua del inga. El idioma regional de Huarochirí, hoy muerta, fue similar al aymara y al idioma moderno del kauki (Taylor, 1983).

22 En el Inventario Comunitario de 1995.
} 
Fuentes secundarias

Abercrombie, Thomas, 1991, “To Be Indian, To Be Bolivian: Ethnic and National Discourses of Identity", en NationStates and Indians in Latin America, Greg Urban y Joel Sherzer (eds.), University of Texas Press, Austin, pp. 95-131.

_ 1988, "The destroying Christ: an Aymara myth of conquest", en Rethinking History and Myth: Indigenous South American Perspectives on the Past, Jonathan D. Hill (ed.) University of Illinois Press, Urbana, Illinois, pp. 50-77.

—_, 1998, Pathways of Memory and Power: Ethnography and History among an Andean People, University of Wisconsin Press, Madison.

Adams, Richard N., 1959, A Community in the Andes, Problems and Progress in Muquiyauyo, The American Ethnological Society / University of Washington Press, Seattle, Washington.

Albó, Xavier, 1999, Andean People in the Twentieth Century. Cambridge History of the Native Peoples of the Americas, vol. 2: South America, Frank Salomon y Stuart Schwartz (eds.), 2da. parte, Cambridge University Press, Nueva York, pp. 765-871.

Allen, Catherine, 1982, "Body and Soul in Quechua Thought", en Journal of Latin American Lore, 8(2): 179-196.

Barragán, Rossana, 1992, "Identidades indias y mestizas: Una intervención al debate", en Autodeterminación, 10: 17-43.

Basso, Ellen, 1985, A Musical View of the Universe, University of Pennsylvania Press, Filadelfia.

Boyarin, Jonathan (ed.), 1993, The Ethnography of Reading, University of California Press, Berkeley.

Bueno Mendoza, Alberto, 1992, "Arqueología de Huarochirí”, en Huarochirí: Ocho mil años de historia, t. 1, Alberto Bueno (ed.), Santa Eulalia de Acopaya, Provincia Huarochirí, Perú, municipalidad de Santa Eulalia de Acopaya, pp. 13-66.

Burga, Manuel, 1988, Nacimiento de una utopía. Muerte y resurrección de los incas, Instituto de Apoyo Agrario, Lima.

Carneiro da Cunha, Manuela y Eduardo Viveiros de Castro, 1985, "Vingança e temporalidade", en Journal de la Sociéte des Américanistes, 71 (1985), pp. 191-208.

Castro Pozo, Hildebrando, 1946, "Social and economicopolitical evolution of the communities of central Perú", en Handbook of South America Indians, Julian Steward (ed.), vol. 2, Smithsonian Institution, Washington, pp. 483-499.

De la Cadena, Marisol, 1996, "The Political Tensions of Representations and Misrepresentations: Intellectuals and mestizas in Cuzco, 1919-1990", en Journal of Latin American Anthropology, 2(1): 112-147.
— 2000, Indigenous Mestizos. The Politics of Race and Culture in Cuzco, Peru, 1919-1991, Duke University Press, Durham.

Escobar, Gabriel, 1973, Sicaya: cambios culturales en una comunidad mestiza andina, Instituto de Estudios Peruanos, Lima.

Flores Galindo, Alberto, 1987, Buscando un inca: Identidady utopía en los Andes, Instituto de Apoyo Agrario, Lima.

Fuenzalida Vollmar, Fernando, 1979, "Los gentiles y el origen de la muerte", en Revista de la Universidad Católica, Lima, 5: 213-222.

Glave, Luis Miguel, 1991, "Los campesinos leen su historia: un caso de identidad recreada y creación colectiva de imágenes. Los comuneros canas en Cusco, Perú”, en Los Andes en la encrucijada. Indios, comunidades, y estado en el siglo XIX, Heraclio Bonilla (ed.), Ediciones Libri Mundi / FLACSO Sede Ecuador, Quito, pp. 221-275.

Gose, Peter, 1994, Deathly Waters and Hungry Mountains. Agrarian Ritual and Class Formation in an Andean Town, University of Toronto, Toronto.

Gudeman, Stephen, y Alberto Rivera, 1995, "From Car to House [Del coche a la casa]", en American Anthropologist, $97(2):$ 242-250.

Guillén Araoz, Teresa, 1953, "La comunidad de Huarochirí", en Revista del Museo Nacional, Lima, 22: 191-230.

Gushiken, José, 1993, Extirpación de la idolatría en la sierra de Lima, Universidad Nacional Mayor de San Marcos, Seminario de Historia Rural Andina, Lima.

Harris, Olivia, 1982, "The dead and the devils among the Bolivian Laymi", en Death and the Regeneration of Life, Maurice Bloch y John Parry (eds.), Cambridge University Press, Londres, pp. 45-73.

Howard-Malverde, Rosaleen, 1994, “'La gente más bien hace guerra con los cuentos': estrategias narrativas en una comunidad quechua del Perú central", en Andean Oral Traditions: Discourse and Literature, Bargot Beyersdorff y Sabine Dedenbach-Salazar (eds.), Bonner Amerikanistische Studien, 24, pp. 117-136.

INEI (Instituto Nacional de Estadística e Informática, Dirección Nacional de Censos y Encuestas, 1994, Censo Nacional 1993. Resultados definitivos, t. 1, núm. 2, Departamento de Lima, Instituto Nacional de Estadística e Informática, Lima.

Isbell, William, 1997, Mummies and Mortuary Monuments: a Postprocessual Prehistory of Central Andean Social Organization, University of Texas Press, Austin.

Janvry, Alain de, 1981, The Agrarian Question and Reformism in Latin America, Johns Hopkins University Press, Baltimore.

Krech, Shepard, 1991, “The State of Ethnohistory”, en Annual Review of Anthropology, 20: 345-375. 
Krupat, Arnold, 1992, "Figures and the Law: Rhetorical readings of Congressional and Cherokee Texts", en EthnoCriticism. Ethnography, History, Literature, University of California Press, Berkeley, pp. 130-172.

Lavallé, Bernard, 1982, "Las doctrinas de indígenas como núcleos de explotación colonial; siglos XVI-XVII", en Alpanchis, 16(19): 151-171.

Long, Norman, y Bryan R. Roberts (eds.), 1978, Peasant Cooperation and Capitalist Expansion in Central Peru, University of Texas, Institute of Latin American Studies, Austin.

Mallon, Florencia E., 1983, The Defense of Community in Peru's Central Highlands, Princeton University Press, Princeton.

Matos Mar, José, 1953, "El proyecto Yauyos-Huarochirí”, en Revista del Museo Nacional, Lima, 22: 179-190.

— (ed.), 1958, Las actuales comunidades indígenas: Huarochiri en 1955, Departmento de Antropología, Facultad de Letras, Universidad Nacional Mayor de San Marcos, Lima.

Ortiz Rescaniere, Alejandro, 1973, De Adaneva a Inkarrí. Una visión indígena del Perú, Retablo de Papel, Lima.

Pærregaard, Karsten, 1987, "Death rituals and symbols in the Andes”, en Folk, 29: 23-42.

Platt, Tristan, 1997, "The Sound of Light: Emergent Communication through Quechua Shamanic Dialogue", en Creating Context in Andean Cultures, Rosaleen Howard-Malverde (ed.), Oxford University Press, Nueva York, pp. 195-226.

Price, Richard, 1990, Alabi’s World, Johns Hopkins University Press, Baltimore.

Poole, Deborah, 1997, Vision, race, and modernity : a visual economy of the Andean image world, Princeton University Press, Princeton, N.J.

Ranger, Terence, 1993, "The local and the global in Southern African religious history", en Conversion to Christianity. Historical and anthropological perspectives on a great transformation, Robert W. Hefner (ed.), University of California Press, Berkeley, pp. 65-98.

Rappaport, Joanne, 1990, The Politics of Memory. Native Historical Interpretation in the Colombian Andes, Cambridge University Press, Nueva York.

— 1994, Cumbe Reborn. An Andean Ethnography of History, University of Chicago Press, Chicago.

Rostworowski de Díez Canseco, María, 1978, "Los Yauyos coloniales y el nexo con el mito", en Señoríos indígenas de Lima y Canta, Instituto de Estudios Peruanos, Lima, pp. 109-122.

Salomon, Frank, 1997, "Los quipus y libros de la Tupicocha de hoy”, en Arqueología, antropología e historia en los An- des. Homenaje a Maria Rostworowski, Rafael Varón Gabai y Javier Flores Espinoza (eds.), Instituto de Estudios Peruanos, Lima, pp. 241-258.

— y Armando Guevara-Gil, 1994, "A 'Personal Visit': Colonial Political Ritual and the Making of 'Indians' in the Andes", en Colonial Latin America Review, 3.

— y George Urioste (eds. y trad.), 1991 [1608], The Huarochiri Manuscript, a Testament of Ancient and Colonial Andean Religion, University of Texas Press, Austin.

Smith, Gavin A., 1989, Livelihood and Resistance: Peasants and the Politics of Land in Peru, University of California Press, Berkeley.

Sotelo, Hildebrando R., 1942, Las insurrecciones y levantamientos en Huarochirí y sus factores determinantes, tesis de doctorado, Facultad de Letras de la Universidad Nacional Mayor de San Marcos, Empresa Periodística "La Prensa", Lima.

Spalding, Karen, 1984, Huarochirí, an Andean society under Inca and Spanish rule, Stanford U. Press, Stanford.

Stern, Steve J., 1982, Peru's Indian Peoples and the Challenge of Spanish Conquest. Huamanga to 1640, University of Wisconsin Press, Madison.

Stiglich, Germán, 1922, Diccionario geográfico del Perú, Imprenta Torres Aguirre, Lima.

Taylor, Gerald, 1983, "Lengua general y lenguas particulares en la antigua provincia de Yauyos (Perú)", en Revista de Indias, 171: 265-289.

Taylor, Gerald (ed. y trad. con Antonio Acosta), 1987, Ritos y tradiciones de Huarochirí del siglo XVII, Instituto de Estudios Peruanos e Instituto Francés de Estudios Andinos, Lima, Historia Andina, núm. 12.

Te Paske, John Jay y Herbert Klein, 1982, The royal treasuries of the Spanish Empire in America, Duke University Press, Durham, N.C.

Thurner, Mark, 1997, From Two Republics to One Divided: Contradictions of Postcolonial Nationmaking in Andean Peru, Duke University Press, Durham.

Tschopik, Harry, Jr., 1947, Highland Communities of Central Peru. A Regional Survey, Smithsonian Institution, Institute of Social Anthropology, publ. núm. 5, Washington.

Urton, Gary, 1990, The History of a Myth. Pacariqtambo and the Origin of the Inkas, University of Texas Press, Austin.

Valderrama Fernández, Ricardo y Carmen Escalante Gutiérrez, 1980, “Apu Qorpuna (visión del mundo de los muertos en la comunidad de Awkimarca), debates en Antropología, 5: 233-269.

Weismantel, Mary J., 1988, Food, Gender, and Poverty in the Ecuadorian Andes, University of Pennsylvania Press, Filadelfia. 